\title{
Association of HLA-DQA2 and HLA-B With Moyamoya Disease in the Chinese Han Population
}

Jiang Wan, MD, Wei Ling, PhD, Zhang Zhengshan, MD, Zuo Xianbo, PhD, Duan Lian, PhD, and Wang Kai, PhD Neurol Genet 2021;7:e592. doi:10.1212/NXG.0000000000000592

\author{
Correspondence \\ Dr. Wang \\ wangkai1964@126.com \\ or Dr. Zuo \\ zuoxianbo@gmail.com \\ or Dr. Duan \\ duanlian307@sina.com
}

\begin{abstract}
Objective

An HLA imputation was conducted to explore the relationship between HLA and patients with moyamoya disease (MMD) in the Chinese Han population.

\section{Methods}

In this study, we performed an association analysis of the major histocompatibility complex region in 2,786 individuals of Chinese Han ancestry (2,031 controls and 755 patients with MMD), through a widely used HLA imputation method.
\end{abstract}

\section{Results}

We identified that the variant rs3129731 (odds ratio $[\mathrm{OR}]=1.79, p=3.69 \times 10^{-16}$ ) located between the MTCO3P1 and HLA-DQA2 is a major genetic risk factor for MMD. In addition to this variant, found in the conditional association analysis, we also detected another independent signal, $\operatorname{rs} 1071817\left(\mathrm{OR}=0.62, p=1.20 \times 10^{-11}\right)$, in HLA-B.

\section{Conclusions}

Our research suggests that the genetic polymorphism of HLA-DQA2 and HLA-B could be a genetic predisposing factor for MMD in Chinese Han. This may provide some evidence for further HLA-related studies of patients with MMD of Chinese Han ethnicity and indicates that MMD is an immune-related disease.

From the Department of Neurology (J.W.), the First Affiliated Hospital of Anhui Medical University, the School of Mental Health and Psychological Sciences, Anhui Medical University,
Hefei, Anhui Province, Department of Neurology (.W.), Drum Tower Hospital, Medical School and the State Key Laboratory of Pharmaceutical Biotechnology, Nanjing University; the
School of Mental Health and Psychological Sciences (W.L.), Anhui Medical University, Anhui Province, Institute of Artificial Intelligence (W.L.), Hefei Comprehensive National Science
Center. Anhui Province Key Laboratory of Cognition and Neuropsychiatric Disorders (W.L.), Hefei; Collaborative Innovation Center of Neuropsychiatric Disorders and Mental Health
(W.L), Anhui Province; Department of Neurosurgery (Z.Z.), the Fifth Medical Centre, Chinese PLA General Hospital (Former 307th Hospital of PLA), Beijing; Department of
Dermatology (Z.X.), the First Affiliated Hospital, Anhui Medical University, Hefei, Anhui Province; Key Laboratory of Dermatology (Z.X.), Anhui Medical University, Ministry of
Education, Hefei, Anhui Province; State Key Lab of Dermatology Incubation Center (Z.X.), Anhui Medical University, Hefei, China; Department of Neurosurgery (D.L.), the Fifth Medical
Centre, Chinese PLA General Hospital (Former 307th Hospital of PLA), Beijing; the School of Mental Health and Psychological Sciences (W.K.), Anhui Medical University, Anhui
Province; Institute of Artificial Intelligence (W.K.), Hefei Comprehensive National Science Center; Anhui Province Key Laboratory of Cognition and Neuropsychiatric Disorders (W.K.),
Hefei, Collaborative Innovation Center of Neuropsychiatric Disorders and Mental Health (W.K.), Anhui Province, China.

Go to Neurology.org/NG for full disclosures. Funding information is provided at the end of the article.

J. Wan, W. Ling, and Z. Zhengshan contributed equally to this article.

The Article Processing Charge was funded by the authors.

This is an open access article distributed under the terms of the Creative Commons Attribution-NonCommercial-NoDerivatives License 4.0 (CC BY-NC-ND), which permits downloading and sharing the work provided it is properly cited. The work cannot be changed in any way or used commercially without permission from the journal. 


\section{Glossary}

GWAS = genome-wide association study; MAF = minor allele frequency; $\mathbf{M H C}=$ major histocompatibility complex; $\mathbf{M M D}=$ moyamoya disease; $\mathbf{O R}=$ odds ratio; $\mathbf{S N P}=$ single nucleotide polymorphism.

Moyamoya disease (MMD) is a chronic, progressive, occlusive cerebrovascular disease of unknown etiology. Its distinctive pathologic feature is the steno-occlusion of the distal internal carotid artery or its proximal branches, with the formation of fragile, small, net-like collaterals. ${ }^{1,2}$ It is initially described in Japan as "moya-moya" for its angiographic characteristics of "a puff of smoke." Epidemiologic studies have found that the incidence of MMD is highest in East Asian countries. ${ }^{1,2}$ The common clinical presentations of MMD include TIA, ischemic stroke, hemorrhagic stroke, seizures, headache, and cognitive impairment. It is a common cause of stroke in children or young adults. ${ }^{4}$ A study has shown that MMD may be caused by genetic factors, rather than environmental factors, ${ }^{5}$ and genetic studies have shown that MMD-related genetic loci exist on chromosomes 3, 6, 8, and $17 .{ }^{6-11}$ Our previous genome-wide association study (GWAS) also confirms the association of MMD with chromosomes 3 and $17 .{ }^{12}$ In addition, we also find enrichment of susceptibility gene expression associated with the immune system. ${ }^{12}$

The major histocompatibility complex (MHC) encodes several key immune response genes and is also known as the HLA region in humans. It is located on chromosome 6p21 and includes a series of closely linked loci. ${ }^{13}$ The MHC gene can be divided into 3 regions, which are named MHC Class I, MHC Class II, and MHC Class III. The most important molecules of the classical human MHC Class I antigens are HLA-A, HLA-B, and HLA-C, whereas MHC Class II antigenrelated molecules are HLA-DR, HLA-DQ, and HLA-DP. ${ }^{14,15}$ The MHC Class III region is located between the Class I and II regions and contains 55 protein coding genes and 5 pseudogenes. ${ }^{16}$ Many MHC gene products are involved in inflammatory responses, as part of the adaptive immune response, and interact with natural killer cell and cytokines as part of the innate immune response. They include ligands for antigen processing and expression, receptors, interacting proteins, signal transduction factors, and transcriptional regulatory factors. ${ }^{16}$ As HLA plays an important role in the immune system, it has received a lot of attention. However, studies have found that it also has important roles in other disease systems. The alleles that encode the HLA molecules have frequently been reported to be strongly associated with various diseases, such as ankylosing spondylitis, reactive arthritis, ${ }^{14}$ Takayasu arteritis, ${ }^{17}$ giant cell arteritis, ${ }^{18}$ granulomatosis with polyangiitis, ${ }^{19}$ and various other autoimmune disorders. ${ }^{14}$ Therefore, the identification of an association between HLA and disease susceptibility has become important to diagnose and understand the pathogenesis of the diseases.
Although some reports have suggested possible linkage with MMD on chromosomes 3p24.2-p26 and 17q25, ${ }^{6-9}$ a marker located on chromosome 6 is also indicated to be in linkage with MMD. ${ }^{7}$ Previous studies reported that some HLA alleles were associated with $\mathrm{MMD}^{20-22}$; however, these investigations are limited, and study cohorts are small, particularly in the Chinese Han population.

We investigated the distributions of HLA genes in Chinese Han patients with MMD to identify HLA markers that may contribute to genetic susceptibility.

\section{Methods}

\section{GWAS Data}

The study data were obtained from our previous MMD GWAS for 755 cases and 2031 controls that were genotyped by HumanOmniZhongHua- 8 BeadChip, which was previously described in our early studies. ${ }^{12}$ All of the cases fulfilled the diagnosis guideline established by the Research Committee on Spontaneous Occlusion of the Circle of Willis (MMD) of the Ministry of Health and Welfare of Japan. 1,23,24 All the cases were diagnosed by digital subtraction angiography or MR angiography, with stenosis of the bilateral internal carotid artery system. According to the guideline, moyamoya syndrome and patients with vasculopathy caused by atherosclerosis, irradiation, meningitis, brain neoplasm, head trauma, Recklinghausen disease, Down syndrome, and autoimmune disease to the head were excluded. The health control groups were recruited such that they matched cases in terms of age, sex, and geographical distribution (birthplace), and controls with a medical history of any cerebrovascular diseases or myocardial infarction were excluded. All the study subjects and single nucleotide polymorphisms (SNPs) were extracted via a standard quality control criteria, exclusion of closely related relative and outliers in terms of ancestry, SNP, and sample call rate $(<90 \%)$, SNP minor allele frequency (MAF) $(<1 \%)$, and Hardy-Weinberg equilibrium $\left(p \leq 10^{-4}\right)$ cutoffs. The study subjects were homogeneous and it showed no evidence of systemic bias or potential population substructure which after the principal component analysis runs to exclude the occurrence of the above.

\section{Standard Protocol Approvals, Registrations, and Patient Consents}

Written informed consent was obtained from all participants. The study was approved by the Ethics Committee of Anhui Medical University and implemented according to the Declaration of Helsinki. 

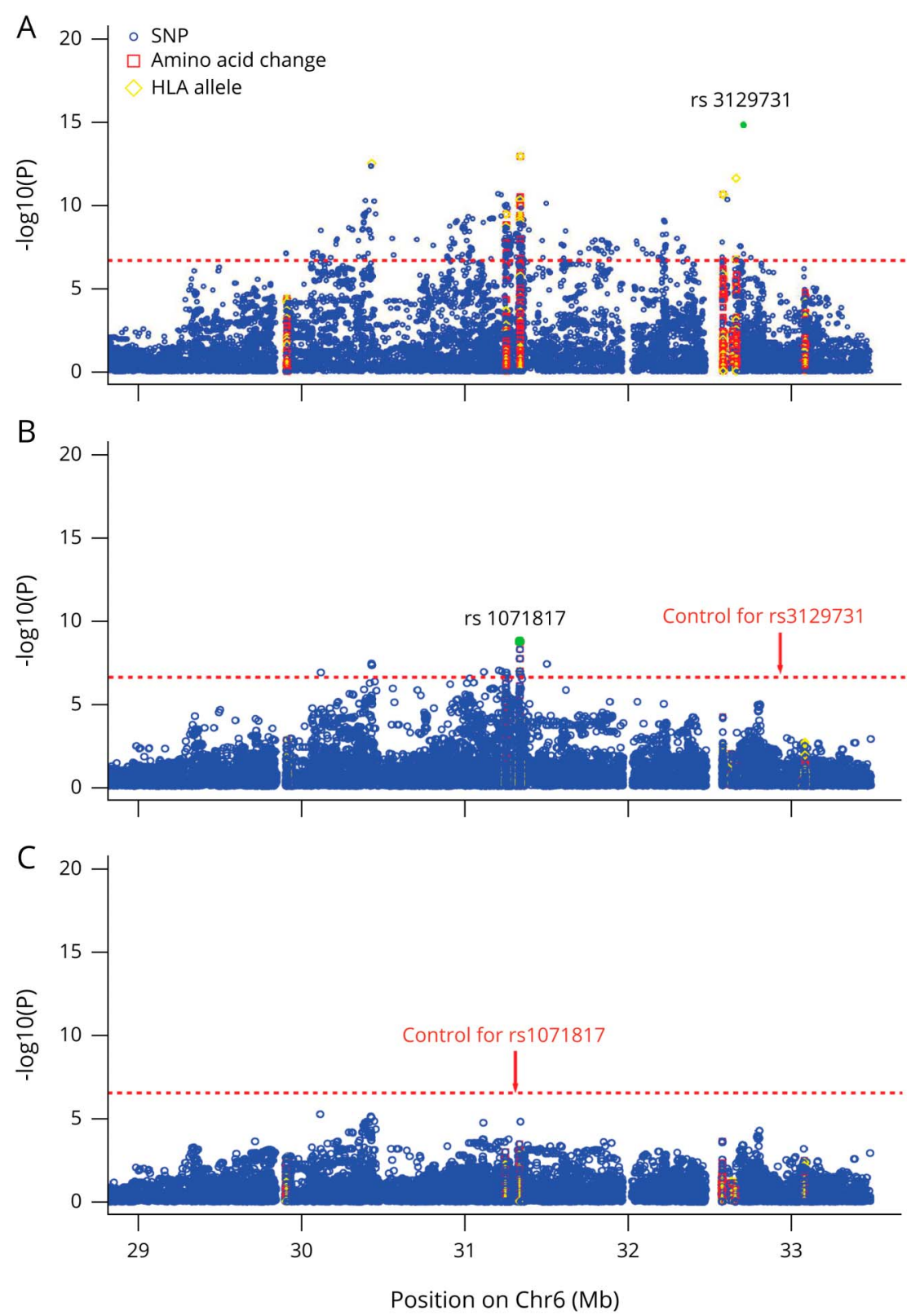

The association of each locus used for conditioning
(rs3129731 and rs1071817) is shown in the green
dot in each panel. In each plot, the horizontal axis
shows the chromosomal position (based on Uni-
versity of California Santa Cruz hg19 assembly) and
the vertical axis shows -log10 ( $p$ value) for associa-
tion with MMD in the logistic regression model. The
horizontal dashed line corresponds to the meaning
threshold $p=5 \times 10^{-8}$

\section{Imputation of the HLA Region}

We extracted SNP genotypes located in the MHC region (29-34 $\mathrm{Mb}$ at chromosome 6) and then imputed 2- and 4-digit classical alleles for HLA-A (MIM 142800), HLA-B (MIM 142830), HLA-C (MIM 142840), HLA-DRB1 (MIM 142857), HLA-DQB1 (MIM 604305), HLA-DQA1 (MIM 146880), HLA-DPB1 (MIM 142858), and HLA-DPA1 (MIM 142880), their corresponding amino acid polymorphisms, and SNPs, on the basis of 2 reference panels: the HLA and SNP genotypes from the 1000 Genomes Project reference data (only the Chinese Han population) ${ }^{25}$ and the Han-MHC database $(n=10,689) .{ }^{26}$ For the postimputed data, the variants, with low imputation quality $\left(\mathrm{r}^{2}<0.10\right)$, or MAF below 0.01 or significant deviation from HardyWeinberg equilibrium $\left(p<1.00 \times 10^{-4}\right.$, software PLINK version 1.07$)$ had been removed. All information about the SNPs, amino acid residues, and 2-digit and 4-digit HLA alleles were encoded as binary variables and phased by the Beagle 3.0.4 imputation program powered by the SNP2HLA method with some modifications.

\section{Association Analysis}

After imputation, we did an association analysis and set a genome-wide significance threshold $\left(p=5.0 \times 10^{-8}\right)$ to find sites with significant association. We determined the top independent associations using a stepwise logistic regression model to explore MMD independent loci, controlling for the most significant sites of $p$ value as covariates in raw date of 
Table 1 Association of HLA Alleles, Amino Acid Polymorphisms, and Single Nucleotide Polymorphisms With Moyamoya Disease Susceptibility

\begin{tabular}{|c|c|c|c|c|c|c|}
\hline \multirow[b]{2}{*}{ Variants } & & \multirow[b]{2}{*}{ A1/A2 } & \multicolumn{2}{|c|}{ Frequency of A1 } & \multirow[b]{2}{*}{ OR (95\% Cl) } & \multirow[b]{2}{*}{$p$ Value } \\
\hline & & & Cases & Control & & \\
\hline HLA allele & $H L A-B * 46$ & $\mathrm{P} / \mathrm{A}$ & 0.07 & 0.14 & $0.49(0.40-0.61)$ & $4.12 \times 10^{-11}$ \\
\hline Amino acid polymorphism & HLA-B amino acid Ala24 & $\mathrm{A} / \mathrm{P}$ & 0.57 & 0.45 & $1.58(1.41-1.78)$ & $3.48 \times 10^{-14}$ \\
\hline \multirow[t]{2}{*}{ SNPs } & rs3129731 & $\mathrm{T} / \mathrm{G}$ & 0.26 & 0.17 & $1.79(1.55-2.06)$ & $3.69 \times 10^{-16}$ \\
\hline & rs1071817 & T/G & 0.21 & 0.3 & $0.62(0.54-0.71)$ & $1.20 \times 10^{-11}$ \\
\hline
\end{tabular}

Abbreviations: $\mathrm{A} 1 / \mathrm{A} 2$ = effective allele/alternative allele; $\mathrm{A} / \mathrm{P}=$ absent/present; $\mathrm{OR}=$ estimated odds ratio; $p=$ statistical logistic $p$ value of each variant; $95 \% \mathrm{Cl}$ : $95 \%$ confidence interval for OR.

Here, we just show the most significant variants; one can refer to others in table e-3, links.Iww.com/NXG/A424.

imputation; then, the results were analyzed, and the $p$ value was found to be significant. The most significant loci was then used as the new control signal and it was taken as the most significant point of the $p$ value as a new signal after control. Then, we selected the most significant point after control as covariates to control, and so on, until no site reaches the significant level $\left(p<5.0 \times 10^{-8}\right)$.

\section{Construction of Protein Spatial Structure}

We queried the target amino acid sequence on GenBank (ncbi.nlm.nih.gov) and used protein homology modeling with the SWISS-MODEL online website (swissmodel.expasy. org). The image was prepared using VMD 1.9.3.

\section{Data Availability}

Anonymized data will be shared by request from any qualified investigator.

\section{Results}

\section{HLA Imputation Result}

From our previous MMD GWAS data, we chose 8,245 SNPs in 755 MMD cases and 2031 controls using an optimized target capture array. After quality control, we finally obtained 6,789 SNPs. Then, using the imputation method, we successfully inferred the 2-digit and 4-digit genotypes of 8 HLA genes, their corresponding amino acid polymorphisms, and the SNPs in the MHC region of the 2,786 subjects. We obtained 29,948 variants. After strict quality control of all variants obtained from imputation, we finally obtained 25,729 variants to further assess their association with the risk of MMD (table e-1, links.lww.com/NXG/ A422).

\section{rs3129731 Has the Strongest Association With MMD Risk}

As shown in figure 1, the top association signal was given by rs3129731 (odds ratio $[\mathrm{OR}]=1.79, p=3.69 \times 10^{-16}$; table 1 ), an intergenic SNP located between the MTC O 3P1 and HLA$D Q A 2$, when the variants in the MHC region were tested for overall risk of $\mathrm{MMD}$ (patients vs control individuals). We also found an HLA allele in HLA-B $\left(H L A-B^{*} 46\right.$, OR $=0.49, p=$ $4.12 \times 10^{-11}$; table 1 ).

\section{HLA-B Associations With MMD in the Chinese Han Population}

We then investigated additional HLA variants that were associated with the risk of MMD but were independent of rs3129731. When conditioning on rs3129731, we observed a significant independent SNP at HLA-B amino acid position 94 $\left(\mathrm{rs} 1071817, \mathrm{OR}=0.62, p=1.20 \times 10^{-11}\right)$ and a most significant amino acid polymorphism (HLA-B amino acid 24 , OR $=1.58$, $\left.p=3.48 \times 10^{-14}\right)$. We then conditioned on rs3129731 and rs1071817 but observed no other significant associations ( $p<$ $\left.5.0 \times 10^{-8}\right)($ table e-2, links.lww.com/NXG/A423). These results indicate that $\mathrm{MMD}$, associated with the MHC region, can be explained by combinations of multiple HLA-B genes.

\section{The 3D Ribbon Model of the HLA Protein}

The HLA-B structure was based on Protein Data Bank entry 6 at5. ${ }^{27}$ The HLA-B amino acid 94 residue is located in a $\alpha$-helix structure, within a peptide-binding groove, and the HLA-B amino acid 24 residue is located in a $\beta$-strand structure at the beginning of the protein peptide chain (figure 2).

The flowchart of the research process can be found in the appendix (figure e-1, links.lww.com/NXG/A421).

\section{Discussion}

We have applied an HLA imputation approach to our previous MMD GWAS data, which was of a well-characterized cohort of 755 Chinese Han patients with MMD and 2031 healthy controls. After correlation analysis, we identified the common variant rs3129731, within the HLA locus, as a main genetic risk factor for acquiring MMD. We also found another independent signal, rs1071817 in HLA-B, by condition analysis.

SNP rs3129731 is located in the intergenic region between the MTCO3P1 and HLA-DQA2. MTCO3P1 (mitochondrially encoded cytochrome $\mathrm{C}$ oxidase III pseudogene 1) is a 
Figure 2 Three-Dimensional Ribbon Models for HLA-B

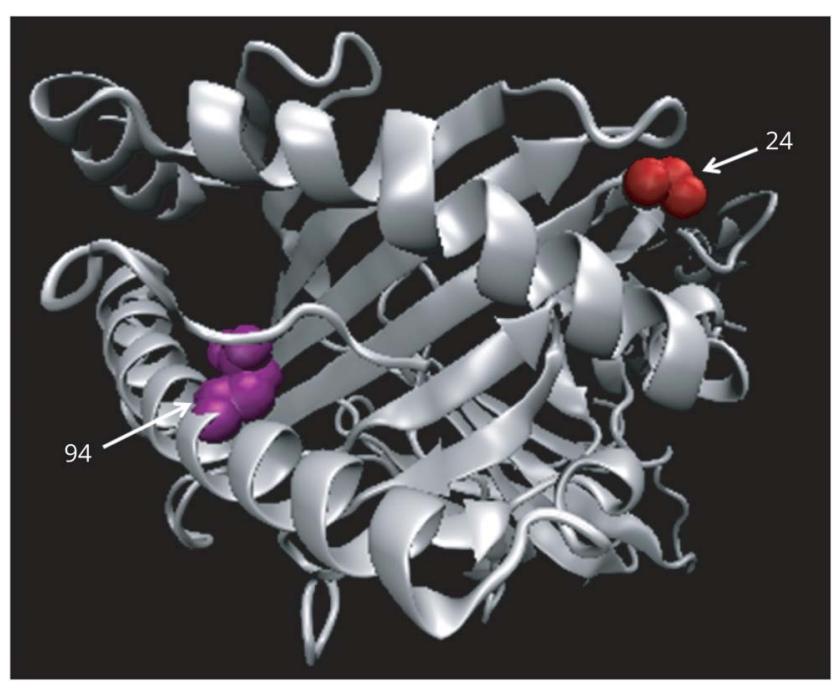

HLA-B amino acid residues 94 and 24 are highlighted in purple and red respectively (for interpretation of the references to colors in this figure legend, the reader is suggested to refer to the web version of this article).

pseudogene and was affiliated with the lncRNA class. HLADQA2 belongs to the HLA Class II alpha chain family. This variant showed a strong association with the expression of HLA-DQA2 in the artery (gtexportal.org/home/). HLA-DQA2 is believed to play a central role in peptide loading of MHC-II molecules. Class II molecules are expressed in antigenpresenting cells (APCs) (B lymphocytes, dendritic cells, and macrophages) and are used to present antigenic peptides to the cell surface, to be recognized by $\mathrm{CD} 4^{+} \mathrm{T}$ cells. Dimer formation with $H L A-D Q B 2$ and $H L A-D Q A 2$ plays an importance role in immunology. ${ }^{28}$ Studies have found that HLA-DQA2 is associated with some autoimmune diseases, such as systemic lupus erythematosus $^{29}$ and rheumatoid arthritis. ${ }^{30}$

In addition, there is an enrichment of amino acid mutations and alleles in the $H L A-D R B$ region. The most significant mutation is at HLA-DRB1 amino acid position 9, which is located on the N-terminal signal peptide. HLA-DRB1 can bind peptides that are derived from antigens, which access the endocytic route of APCs. The peptides are presented on the cell surface for recognition by $\mathrm{CD}^{+} \mathrm{T}$ cells. Studies have found that some $\mathrm{CD}^{+} \mathrm{T}$ cells are unique because they are strongly cytotoxic and have the ability to directly kill cells infected with virus. This HLA Class II molecule is known to be involved, which provides insights into how specific $\mathrm{CD}^{+}$ $\mathrm{T}$ cells may participate in vascular immunopathology. ${ }^{31}$

In Japanese patients, a significant association of HLA-DR1 with MMD is reported $(p<0.05) . .^{32}$ It is also reported that HLA$D R B 1^{*} 1501$ and $H L A-D Q B 1^{*} 0502$ are associated with MMD. ${ }^{22,33}$ In Korean patients, HLA-DRB1 1302 and HLA$D Q B 1^{*} 0609$ showed an association in familial patients (Unpublished data). ${ }^{14} \mathrm{We}$ also found some significant association in both $H L A-D Q B$ and $H L A-D R B$, and we observed that amino acid mutations and allele frequencies were enriched in the HLA-DRB1 gene region. These results suggest that although there are differences between HLA and MMD in Japanese, Korean, and Han patients, there are some similarities.

We also found another significant variant, rs1071817, when comparing patients with controls. This variant maps to the $H L A-B$ gene and encodes amino acid 94 of HLA-B. We found 1 nonsense variant, with a gain of stop signal, and 2 missense variants at this site. Amino acid 94 of HLA-B is located in the alpha 1 chain of the MHC-I molecule and is located outside the cell membrane. This chain may be responsible for binding to peptides. In addition to amino acid 94 of HLA-B, we found other amino acid polymorphisms in HLA-B such as amino acid 24 of HLA-B, which is located in a $\beta$-strand structure (table e-3, links.lww.com/NXG/A424). Those variations may lead to changes in the function of the alpha 1 chain of the MHC-I molecule by affecting the normal synthesis. Associations of HLA-B46 and B54 ( $p<0.05$ or $<0.025$ ) with the risk of MMD in Japanese patients with MMD were reported in the early $1980 \mathrm{~s}^{20}$ A significant association with HLA-B67 was found in an investigation of 32 unrelated Japanese patients with $M M D .^{21}$ It revealed the association of HLA-B35 with females in the late-onset group of individuals with MMD in the Korean population. ${ }^{32}$ In our study, we observed that amino acid mutations and allele frequencies were significantly enriched in the HLA-B gene region, and we also found some of the HLA alleles described above. However, only HLA-B46 showed a significant difference between case and control $\left(p=4.12 \times 10^{-11}\right)$. Several studies showed that HLA-B46 may also be associated with Graves disease. $^{34,35}$

By applying autoimmunity and inflammation classification gene chips, a study found differential expression in 32 genes in the peripheral blood of patients with $\mathrm{MMD}$, compared with healthy controls. After searching the gene pool, 23 of the genes were related to cellular immunity and 9 were related to humoral immunity. ${ }^{36}$ In our study, significant association was found between HLA Class I and II genes and the risk of MMD. Both these genes are important components of humoral immunity and cellular immunity, which suggests that both types of immunity are involved in MMD. Another epidemiologic study found that $8.5 \%$ of patients with MMD had type I diabetes, which is significantly higher than in the average US population $(8.5 \%$ vs $0.4 \%, p<0.001) .{ }^{37,38}$ The prevalence of autoimmune thyroid disease (Graves disease and thyroiditis) in the moyamoya cohort was $17 \%$, which is also significantly higher than that of the general population in the United States $(17 \%$ vs $8.0 \%, p<0.01) .{ }^{38}$ Previous reports suggest that viral and bacterial infection may be involved in the pathogenesis of $\mathrm{MMD}^{39,40}$ and the autoimmune antibody is recognized more frequently in patients with MMD. ${ }^{41,42}$ Through the imputation approach, our data also indicate that MMD may be an immune-related disease and comorbid with autoimmune diseases. 
Although this study provides interesting insights about HLA variants of MMD, it still has some limitations. First, the imputation will be some deviations; to reduce deviations, we referenced the most comprehensive panel of Chinese population at present ${ }^{26}$ and carried strict quality controls. Second, because of extensive linkage disequilibrium, high polymorphism, and strong genetic heterogeneity in the MHC region, ${ }^{43,44}$ the genetic variation that we could capture was limited, and we excluded the rare variations with an MAF of less than $1 \%$ in the MHC region. Therefore, we may show association only between part of the MHC region and MMD. Further functional studies are required to reveal the exact role of the identified variants.

We have shown by imputation that the genetic predisposition to MMD in Chinese Han is associated with HLA. The variants rs3129731 and rs1071817 were significantly associated with the disease in this population. Our findings suggest that the genetic polymorphisms of HLA$D Q A 2$ and $H L A-B$ could be genetic predisposing factors for MMD in Chinese Han. This may provide some evidence for further HLA-related studies of patients with MMD with Chinese Han ethnicity and further suggests that MMD is an immune-related disease.

\section{Acknowledgment}

The authors are grateful to all study participants and study staff.

\section{Study Funding}

The National Key Research and Development Program of China (2016YFC1300600, 2016YFC1306400), the National Natural Science Foundation of China (91432301).

\section{Disclosure}

The authors report no conflict of interest concerning the materials or methods used in this study or the findings specified in this article. Go to Neurology.org/NG for full disclosures.

\section{Publication History}

Received by Neurology: Genetics November 17, 2020. Accepted in final form March 15, 2021.

Appendix Authors

\begin{tabular}{lll}
\hline Name & Location & Contribution \\
\hline Jiang Wan, & $\begin{array}{l}\text { Department of Neurology, } \\
\text { the First Affiliated Hospital of } \\
\text { MD }\end{array}$ & $\begin{array}{l}\text { Acquisition of data, drafting } \\
\text { the article, reviewed }\end{array}$ \\
& $\begin{array}{l}\text { School of Mental Health and } \\
\text { Psychological Sciences, } \\
\text { Anhui Medical University, } \\
\text { Hefei, Anhui Province, China }\end{array}$ & $\begin{array}{l}\text { manuscript, approved the } \\
\text { final version of the manuscript } \\
\text { on behalf of all authors, } \\
\text { statistical analysis, and } \\
\text { critically revising the article }\end{array}$ \\
& & \\
\end{tabular}

Appendix (continued)

\begin{tabular}{lll}
\hline Name & Location & Contribution \\
\hline Wei Ling, & $\begin{array}{l}\text { Institute of Artificial } \\
\text { Intelligence, Hefei } \\
\text { Comprehensive National } \\
\text { Science Center, China }\end{array}$ & $\begin{array}{l}\text { Acquisition of data, drafting } \\
\text { the article, reviewed the }\end{array}$ \\
& $\begin{array}{l}\text { submitted version of the } \\
\text { manuscript, approved the } \\
\text { final version of the } \\
\text { manuscript on behalf of all } \\
\text { authors, statistical analysis, } \\
\text { and critically revising the } \\
\text { article }\end{array}$ \\
& & \\
& & \\
& &
\end{tabular}

\begin{tabular}{|c|c|c|}
\hline $\begin{array}{l}\text { Zhang } \\
\text { Zhengshan, } \\
\text { MD }\end{array}$ & $\begin{array}{l}\text { Department of } \\
\text { Neurosurgery, the Fifth } \\
\text { Medical Centre, Chinese PLA } \\
\text { General Hospital (Former } \\
\text { 307th Hospital of PLA), } \\
\text { Beijing, China }\end{array}$ & $\begin{array}{l}\text { Acquisition of data, drafting } \\
\text { the article, reviewed the } \\
\text { submitted version of the } \\
\text { manuscript, approved the } \\
\text { final version of the } \\
\text { manuscript on behalf of all } \\
\text { authors, statistical analysis, } \\
\text { and critically revising the } \\
\text { article }\end{array}$ \\
\hline
\end{tabular}

Zuo Xianbo, Department of Dermatology, Conception and design,

PhD the First Affiliated Hospital, analysis and interpretation of Anhui Medical University, data, study supervision, and Hefei, Anhui Province, China critically revising the article

\begin{tabular}{lll}
\hline $\begin{array}{l}\text { Duan Lian, } \\
\text { PhD }\end{array}$ & $\begin{array}{l}\text { Department of } \\
\text { Neurosurgery, the Fifth } \\
\text { Medical Centre, Chinese PLA } \\
\text { General Hospital (Former } \\
\text { 307th Hospital of PLA), } \\
\text { Beijing, China }\end{array}$ & $\begin{array}{l}\text { Conception and design, } \\
\text { administrative/technical/ } \\
\text { material support, and } \\
\text { critically revising the article }\end{array}$ \\
\hline $\begin{array}{l}\text { Wang Kai, } \\
\text { PhD }\end{array}$ & $\begin{array}{l}\text { School of Mental Health and } \\
\text { Psychological Sciences, } \\
\text { Anhui Medical University, } \\
\text { Anhui Province, China }\end{array}$ & $\begin{array}{l}\text { Conception and design, } \\
\text { study supervision, and } \\
\text { critically revising the article }\end{array}$ \\
&
\end{tabular}

\section{References}

1. Kim JS. Moyamoya disease: epidemiology, clinical features, and diagnosis. J Stroke 2016;18:2-11.

2. Kleinloog R, Regli L, Rinkel GJ, et al. Regional differences in incidence and patient characteristics of moyamoya disease: a systematic review. J Neurol Neurosurg 2012;83: 531-536.

3. Kudo T. Spontaneous occlusion of the circle of Willis. A disease apparently confined to Japanese. Neurology 1968;18(5):485-496.

4. Kuriyama S, Kusaka Y, Fujimura M, et al. Prevalence and clinicoepidemiological features of moyamoya disease in Japan. Stroke 2008;39:42.

5. Fukui M. Current state of study on moyamoya disease in Japan. Surg Neurol 1997; 47(2):138-143.

6. Ikeda H, Sasaki T, Yoshimoto T, et al. Mapping of a familial moyamoya disease gene to chromosome 3p24.2-p26. Am J Hum Genet 1999;64:533-537.

7. Inoue TK, Ikezaki K, Sasazuki T, et al. Linkage analysis of moyamoya disease on chromosome 6. J Child Neurol 2000;15:179-182.

8. Sakurai K, Horiuchi Y, Ikeda H, et al. A novel susceptibility locus for moyamoya disease on chromosome 8q23. J Hum Genet 2004;49:278-281.

9. Yamauchi $\mathrm{T}$, Tada $\mathrm{M}$, Houkin $\mathrm{K}$, et al. Linkage of familial moyamoya disease (spontaneous occlusion of the circle of Willis) to chromosome 17q25. Stroke 2000;31: 930.

10. Mineharu Y, Liu W, Inoue K. Autosomal dominant moyamoya disease maps to chromosome 17q25.3. Neurology 2008;70:7.

11. Roder C, Nayak NR, Khan N, et al. Genetics of moyamoya disease. J Hum Genet 2010; 55:711-716.

12. Duan L, Wei L, Tian Y, et al. Novel susceptibility loci for moyamoya disease revealed by a genome-wide association study. Stroke 2018;49:11-18.

13. Horton R, Wilming L, Rand V, et al. Gene map of the extended human MHC. Nat Rev Genet 2004;5:889-899.

14. Park MH, Hong SH, Wang K-C. HLA studies in moyamoya disease. Springer 2010: 54-59.

15. Müller CR, Ehninger G. Gene and haplotype frequencies for the loci hLA-A, hLA-B, and hLA-DR based on over 13,000 German blood donors. Hum Immunol 2003;64:5.

16. Shiina $\mathrm{T}$, Hosomichi $\mathrm{K}$, Inoko $\mathrm{H}$, et al. The HLA genomic loci map: expression, interaction, diversity and disease. J Hum Genet 2009;54:15-39.

17. Lv N, Wang Z, Dang A, et al. HLA-DQA1, DQB1 and DRB1 alleles associated with Takayasu arteritis in the Chinese Han population. Hum Immunol 2015;76(4): 241-244. 
18. Carmona FD, Mackie SL, Martín JE, et al. A large-scale genetic analysis reveals a strong contribution of the HLA class II region to giant cell arteritis susceptibility. Am J Hum Genet 2015;96(4):565-580.

19. Watts RA, MacGregor AJ, Mackie SL. HLA allele variation as a potential explanation for the geographical distribution of granulomatosis with polyangiitis. Rheumatology 2015;54(2):359-362.

20. Kitahara T, Okumura K, Semba A, et al. Genetic and immunologic analysis on moyamoya. J Neurol Neurosurg 1982;45:1048.

21. Aoyagi M, Ogami K, Matsushima Y. Human leukocyte antigen in patients with moyamoya disease. Stroke 1995;26(3):415-417.

22. Inoue TK, Ikezaki K, Sasazuki T, et al. Analysis of class II genes of human leukocyte antigen in patients with Moyamoya disease. Clin Neurol Neurosur 1997;99:S234-S237.

23. Research Committee on the Pathology and Treatment of Spontaneous Occlusion of the Circle of Willis, Health Labour Sciences Research Grant for Research on Measures for Intractable Diseases: Guidelines for diagnosis and treatment of moyamoya disease (Spontaneous Occlusion of the Circle of Willis). Neurol Med Chir (Tokyo) 2012; 52(5):245-266.

24. Tominaga T, Suzuki N, Miyamoto S, et al. Recommendations for the management of moyamoya disease: a statement from research committee on spontaneous occlusion of the circle of Willis (moyamoya disease) [2nd Edition]. Surg Cereb Stroke 2018; 46(1):136-140 (Jpn).

25. Marchini J, Howie B, Myers S, McVean G, Donnelly P. A new multipoint method for genome-wide association studies by imputation of genotypes. Nat Genet 2007;39: 906-913.

26. Zhou F, Cao H, Zuo X, et al. Deep sequencing of the MHC region in the Chinese population contributes to studies of complex disease. Nat Genet 2016;48:740.

27. Chan KF, Gully BS, Gras S, et al. Divergent T-cell receptor recognition modes of HLA-I restricted extended tumour-associated peptide. Nat Commun 2018;9(1): 1026.

28. Lenormand $\mathrm{C}$, Bausinger $\mathrm{H}$, Gross $\mathrm{F}$, et al. HLA-DQA2 and HLA-DQB2 genes are specifically expressed in human Langerhans cells and encode a new HLA class II molecule. J Immunol 2012;188:3903-3911.

29. Chung SA, Taylor KE, Graham RR, et al. Differential genetic associations for systemic lupus erythematosus based on anti-dsDNA autoantibody production. PLoS Genet 2011;7(3):e1001323.
30. Lee YH, Bae SC, Choi SJ, et al. Genome-wide pathway analysis of genome-wide association studies on systemic lupus erythematosus and rheumatoid arthritis. $\mathrm{Mol}$ Biol Rep 2012;39:10627-10635.

31. Pachnio A, Ciaurriz M, Begum J, et al. Cytomegalovirus infection leads to development of high frequencies of cytotoxic virus-specific CD4+ T cells targeted to vascular endothelium. Plos Pathog 2016;12(9):e1005832.

32. Han H, Pyo CW, Yoo DS, et al. Associations of moyamoya patients with HLA class I and class II alleles in the Korean population. J Korean Med Sci 2003;18:5.

33. Inoue TK, Ikezaki K, Sasazuki T, et al. DNA typing of HLA in the patients with moyamoya disease. Jpn J Hum Genet 1997;42:507.

34. Au WY, Hawkins BR, Lie AKW, et al. Association of the HLA A2-B46-DR9 haplotype with autoimmune thyroid dysfunction after bone marrow transplantation in Chinese patients. Br J Haematol 2001;115:660-663.

35. Au WY, Lie AK, Kung AW, et al. Autoimmune thyroid dysfunction after hematopoietic stem cell transplantation. Bone Marrow Transpl 2005;35(4):383-388.

36. Huang S, Guo ZN, Shi M, et al. Etiology and pathogenesis of Moyamoya Disease: an update on disease prevalence. Int J Stroke 2017;12(3):246-253.

37. Bower RS, Mallory GW, Nwojo M, et al. Diabetes mellitus and the Moyamoya syndrome. Ann Intern Med 2012;157(5):387-388.

38. Bower RS, Mallory GW, Nwojo M, et al. Moyamoya disease in a primarily white, Midwestern US population: increased prevalence of autoimmune disease. Stroke 2013;44:1997-1999.

39. Tanigawara T, Yamada H, Sakai N, et al. Studies on cytomegalovirus and Epstein-Bar virus infection in moyamoya disease. Clin Neurol Neurosurg 1997;99:S225-S228.

40. Yamada H, Deguchi K, Tanigawara T, et al. The relationship between moyamoya disease and bacterial infection. Clin Neurol Neurosurg 1997;99:S221-S224.

41. Wanifuchi H, Kagawa M, Takeshita M, et al. Autoimmune antibody in moyamoya disease. No Shinkei Geka 1986;14:31-35.

42. Sigdel TK, Shoemaker LD, Chen R, et al. Immune response profiling identifies autoantibodies specific to Moyamoya patients. Orphanet J Rare Dis 2013;8:45.

43. de Bakker PI, McVean G, Sabeti PC, et al. A high-resolution HLA and SNP haplotype map for disease association studies in the extended human MHC. Nat Genet 2006;38: 1166-1172.

44. Horton R, Gibson R, Coggill P, et al. Variation analysis and gene annotation of eight MHC haplotypes: the MHC haplotype project. Immunogenetics 2008;60:1-18. 


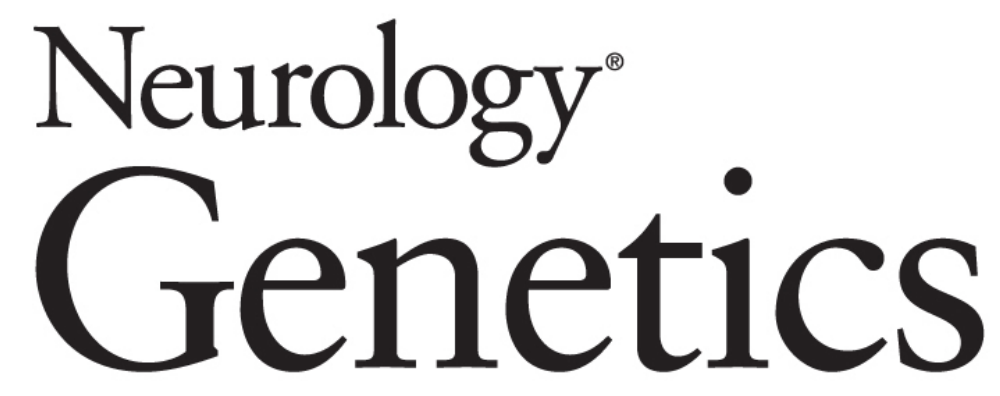

\section{Association of $H L A-D Q A 2$ and $H L A-B$ With Moyamoya Disease in the Chinese Han Population}

Jiang Wan, Wei Ling, Zhang Zhengshan, et al.

Neurol Genet 2021;7;

DOI 10.1212/NXG.0000000000000592

This information is current as of June 2, 2021

\section{Updated Information \&} Services

References

Permissions \& Licensing

Reprints including high resolution figures, can be found at: http://ng.neurology.org/content/7/3/e592.full.html

This article cites 43 articles, 8 of which you can access for free at: http://ng.neurology.org/content/7/3/e592.full.html\#\#ref-list-1

Information about reproducing this article in parts (figures,tables) or in its entirety can be found online at:

http://ng.neurology.org/misc/about.xhtml\#permissions

Information about ordering reprints can be found online: http://ng.neurology.org/misc/addir.xhtml\#reprintsus

Neurol Genet is an official journal of the American Academy of Neurology. Published since April 2015, it is an open-access, online-only, continuous publication journal. Copyright Copyright @ 2021 The Author(s). Published by Wolters Kluwer Health, Inc. on behalf of the American Academy of Neurology.. All rights reserved. Online ISSN: 2376-7839.

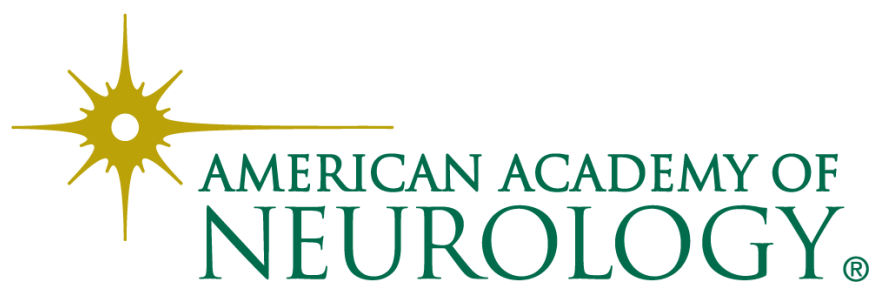

